\title{
Scintigraphic Diagnosis of Intrathoracic Splenic Implants Masquerading as Malignancy
}

\author{
Paul D. Rodrigue, Asif A. Fakhri, and Jin T. Lim
}

Department of Nuclear Medicine and Molecular Imaging, Jacobs School of Medicine and Biomedical Sciences, University at Buffalo, Buffalo, New York

\begin{abstract}
After significant trauma to the spleen, small viable splenic fragments may exist in the peritoneal cavity or, less commonly, in the thorax. Thus, the appearance of splenules within the thorax on CT images can easily be mistaken for malignancy and lead to unnecessary intervention. Here, we present a case of multiple pulmonary masses that initially were presumed to be malignancy, leading to CT-guided biopsy, but were eventually confirmed to be thoracic splenules through ${ }^{99 m T c-l a b e l e d ~ s u l f u r ~}$ colloid scintigraphy.
\end{abstract}

Key Words: correlative imaging; ${ }^{99 m}$ Tc sulfur colloid; splenosis; splenic trauma

J Nucl Med Technol 2016; 44:267-268

DOI: $10.2967 /$ jnmt.116.178616

F or evaluation of liver and spleen disease, ${ }^{99 \mathrm{~m} T c-l a b e l e d}$ sulfur colloid scintigraphy is a reliable noninvasive technique. Visualization of radiotracer uptake on ${ }^{99 \mathrm{~m}} \mathrm{Tc}$-sulfur colloid scintigraphy usually indicates normally functioning hepatic and splenic tissue. Here, we present a case of thoracic splenosis detected on ${ }^{99 \mathrm{~m} T c-l a b e l e d ~ s u l f u r}$ colloid scintigraphy in a patient with a remote history of splenectomy for a gunshot wound.

\section{CASE REPORT}

A 46-y-old woman with a remote history of gunshot wound to the abdomen was admitted to the emergency room complaining of abdominal pain. She also indicated a history of chronic nonbloody productive coughing, which she attributed to her 45 -year history of smoking. CT of the abdomen and pelvis demonstrated a tissue density measuring $4.2 \mathrm{~cm}$ above the left diaphragm. Because no prior images were available, malignancy was suspected. Thus, a needle biopsy guided by dedicated chest CT was performed because of the patient's smoking history.

\footnotetext{
Received May 24, 2016; revision accepted Jul. 5, 2016.

For correspondence or reprints contact: Asif A. Fakhri, University at Buffalo, Jacobs School of Medicine and Biomedical Sciences, Department of Nuclear Medicine and Molecular Imaging, 105 Parker Hall, 3435 Main St., Buffalo, NY 14214.

E-mail: asiffakh@buffalo.edu

Published online Aug. 4, 2016.

COPYRIGHT (C) 2016 by the Society of Nuclear Medicine and Molecular Imaging, Inc.
}

The images (Fig. 1) revealed at least 7 nonspecific softtissue densities in the left hemithorax, with no other signs of trauma. Because there was no spleen in the left upper abdomen, a ${ }^{99 \mathrm{~m} T c-l a b e l e d ~ s u l f u r}$ colloid scan was suggested to confirm accessory splenic tissue. The patient was subsequently injected with $303.4 \mathrm{MBq}(8.2 \mathrm{mCi})$ of 99m Tc-labeled sulfur colloid, and planar and SPECT images were acquired. The images revealed elevated radiotracer uptake by implanted tissue thought to be of splenic origin (Fig. 2). Histopathology from the CT-guided biopsy confirmed these findings of thoracic splenosis.

\section{DISCUSSION}

Because of the patient's remote history of gunshot wound to the abdomen and evidence of posttraumatic splenectomy more than 20 years previously, the soft-tissue masses were easily confirmed as being of splenic origin. Tobacco use increases the incidence of malignancy in the lungs, gastrointestinal tract, liver, kidneys, and bladder (1), among other locations. Unexplained ectopic tissue in these organs must therefore be further worked up. Similarly, splenic implants may be mistaken for lung cancer (2), renal cancer, and peritoneal seeding in patients with a history of bladder

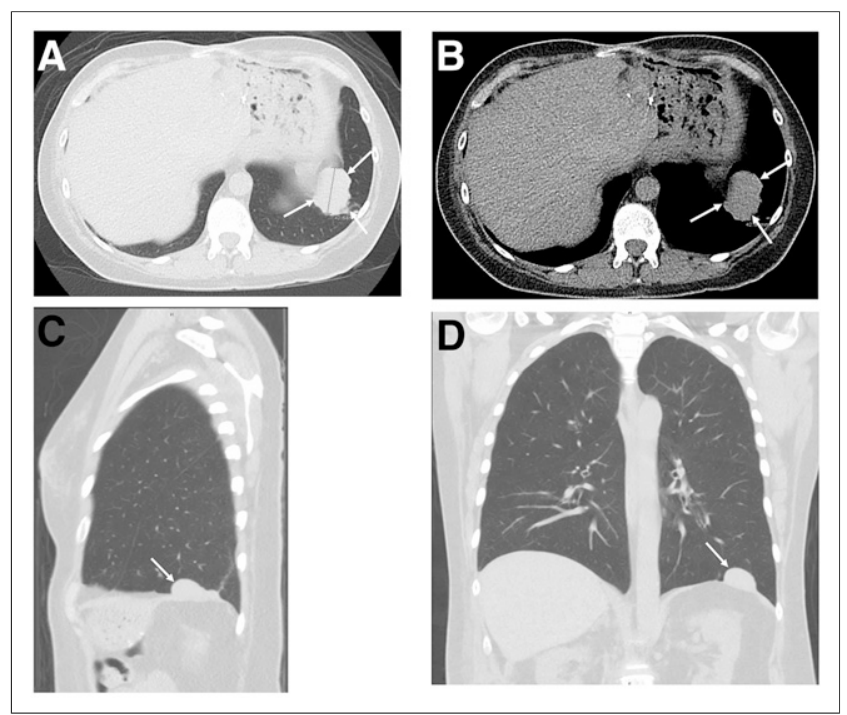

FIGURE 1. Unenhanced CT chest images reformatted in axial ( $A$ and $B$ ), sagittal $(C)$, and coronal (D) projections showing intrathoracic soft-tissue mass abutting left hemidiaphragm (arrows). 
FIGURE 2. 99mTc-labeled sulfur colloid planar images in anterior and posterior projections (A) and SPECT images in coronal projection $(B)$ showing radiotracer uptake by thoracic masses (arrows). These findings confirmed tissue to be of splenic origin.

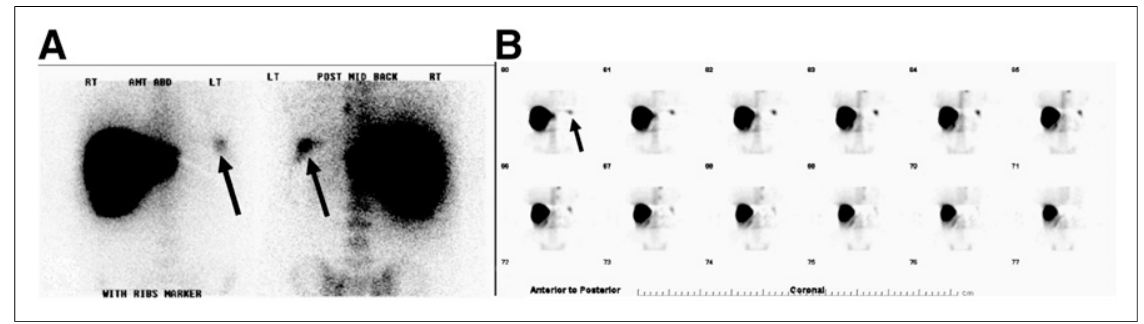

carcinoma, primary or metastatic hepatic malignancy (3), or nonmalignant causes such as endometriosis (4). Given the patient's long history of smoking, the likelihood of malignancy could not be comfortably excluded and further work-up was necessary.

In a patient with a history of trauma requiring splenectomy, we may expect to find splenic implants in the abdomen and pelvis, with intrathoracic implants being a remote possibility. According to the 2015 ACR-SPR guidelines for spleen scintigraphy, if there is suspicion that trauma may have ruptured the diaphragm, the chest should be imaged as well. (5). Additionally, in an effort to preserve some immune functionality, surgeons may attempt autotransplantation of splenic tissue, which will then be evident on imaging with ${ }^{99 \mathrm{~m}}$ Tc-labeled heat-damaged red blood cells or ${ }^{99 \mathrm{~m}}$ Tc-labeled sulfur colloid (6). Figure 2 demonstrates increased radiotracer uptake by the pulmonary masses in the thorax after injection of ${ }^{99 \mathrm{~m} T c-l a b e l e d ~ s u l f u r ~ c o l l o i d, ~ d e m o n s t r a t i n g ~ b e n i g n ~ e c t o p i c ~}$ intrathoracic splenosis.

\section{CONCLUSION}

This case demonstrates that scintigraphy using the readily available tracer ${ }^{99 \mathrm{~m}} \mathrm{Tc}-$ labeled sulfur colloid can be an easy confirmatory test in a patient with suspected thoracic splenosis, thus eliminating the need for invasive tissue biopsy.

\section{DISCLOSURE}

No potential conflict of interest relevant to this article was reported.

\section{REFERENCES}

1. Sasco AJ, Secretan MB, Straif K. Tobacco smoking and cancer: a brief review of recent epidemiological evidence. Lung Cancer. 2004;45(suppl 2): S3-S9.

2. Mpe M, Schauer C. Images in clinical medicine: splenosis mimicking cancer. $N$ Engl J Med. 2016;374:1965.

3. Lin WC, Lee RC, Chiang JH, et al. MR features of abdominal splenosis. AJR. 2003; 180:493-496.

4. Zitzer P, Pansky M, Maymon R, et al. Pelvic splenosis mimicking endometriosis, causing low abdominal mass and pain. Hum Reprod. 1998;13:16831685 .

5. Metter DF, Elman S, Shreve PD, et al. ACR-SPR practice parameter for the performance of liver and spleen scintigraphy. American College of Radiology website. http://www.acr.org/ /media/ACR/Documents/PGTS/guidelines/Liver_ Spleen_Scintigraphy.pdf. Published 1996. Last revised 2015. Accessed September 12, 2016.

6. Khosravi MR, Margulies DR, Alsabeh R, et al. Consider the diagnosis of splenosis for soft tissue masses long after any splenic injury. Am Surg. 2004;70:967970 . 